Initially he was thought to be mentally retarded, which was based on developmental testing and a pneumoencephalogram at 10 months which was suggestive of cerebral atrophy. He walked independently at 2 years. He spent his first 1 to 2 years in an institution for the mentally retarded but was then placed in a foster home. At school age it was evident that he was not retarded and he returned to live with his parents. At the age of 7 he had one grand mal seizure but has had none since. A brain scan at that time was normal. Vertebral radiographs disclosed fusion at $\mathrm{C} 2-3$. $\mathrm{He}$ completed grade XII in a regular high school programme, did two years of college, and is presently in an electronics technology programme. He is a bright, alert, apparently happy, well adjusted man despite his early institutional and foster home experiences including many admissions to hospital.

His general health is good. Examination disclosed the following: height $156.5 \mathrm{~cm}$ (height age 13), head circumference $52.8 \mathrm{~cm}$ ( $<2$ centile), arm span $150 \mathrm{~cm}$, markedly overweight, left esotropia, normal visual acuity, bilateral ptosis left more than right, flat midface, prominent nose, and normal ears. His skull is markedly brachycephalic (figure) and he has a high $\mathrm{V}$ shaped palate with single uvula and mobile soft palate. There is malocclusion with an open bite and he has only 21 teeth consisting of primary and permanent teeth. His speech is normal. He has bilateral simian creases and bilateral short fifth digits, the thumbs appear stubby, and four out of 10 digits show loop radial patterns, three have whorls, and three loop ulnar patterns. They all show a very high pattern intensity. The ATD angles are $45^{\circ}$ and $43^{\circ}$. His lower limbs are normal above the knee; below that he has markedly hypoplastic calves with feet in valgus position and virtually no movement at the ankles. There is normal sensory distribution in the lower limbs.

In summary, this young man has done extremely well and if geneticists encounter similar cases they can at least give some positive information about the possible outcome. I realise, of course, that this is only one case but, nevertheless, the knowledge does provide some sort of guidance to other geneticists.

The author would like to thank the patient and his father for their cooperation and his medical practitioner and endocrine consultant (Drs R G Orchard and G E Wilkins) who provided some clinical and laboratory information, also Marie Bruce for secretarial assistance. Financial support from the

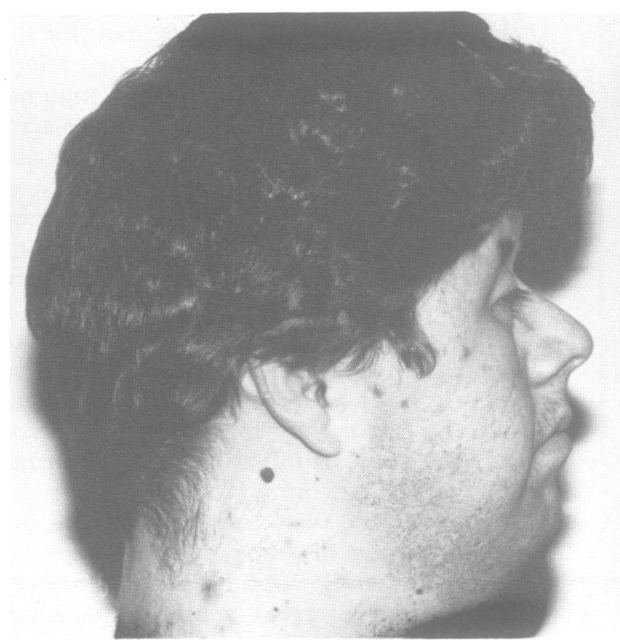

$A P$ and lateral view of the proband showing ptosis, brachycephaly, and prominent nose.

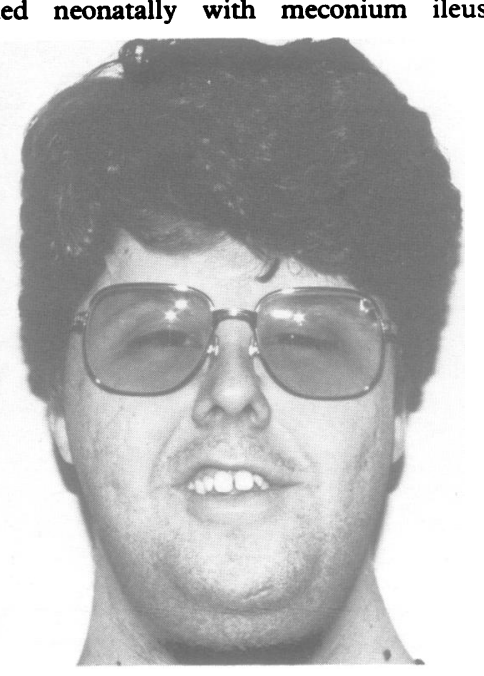

Alberta Children's Hospital Foundation and the Medical Research Council of Canada Grant No 4539 is gratefully acknowledged.

R BRIAN LOWRY Division of Medical Genetics, Department of Paediatrics, University of Calgary Alberta Children's Hospital Research Centre, 1820 Richmond Road SW, Calgary, Alberta T2T 5C7, Canada.

1 Lowry RB. Congenital absence of the fibula and craniosynostosis in sibs. $\mathcal{f}$ Med Genet 1972;9:227-9.

\section{Mild pulmonary, but severe hepatic disease in a cystic fibrosis patient homozygous for a frameshift mutation in the regulatory domain of the CFTR}

The clinical phenotype of cystic fibrosis (CF) patients is very variable and it has been suggested that patients lacking the cystic fibrosis transmembrane conductance regulator (CFTR) have milder lung disease than those having an altered CFTR. ${ }^{1-5}$ However, on the basis of the large variation in lung function in patients homozygous for the most common CF mutation, $\Delta \mathrm{F} 508$, and $\mathrm{W} 1282 \mathrm{X}$ homozygotes, ${ }^{6}$ it was concluded that most CF patients have a common phenotype, but that other genetic and environmental factors may be important for the clinical phenotype.? We describe a patient, homozygous for a frameshift mutation in the regulatory $(R)$ domain of the CFTR, who presented with mild lung disease but severe hepatic and pancreatic involvement. The mutation, 2184delA (deletion of $\mathrm{A}$ at position 2184 together with an $A$ to $G$ substitution at position 2183 in exon 13) was originally characterised by D Bozon and L-C Tsui (personal communication) and was found in both parents of our patient in a screening programme of non- $\Delta \mathrm{F} 508 \mathrm{CF}$ chromosomes with denaturing gradient gel electrophoresis, followed by sequencing.

The boy was born at term in December 1977 , birth weight $3500 \mathrm{~g}$, to healthy, nonconsanguineous parents. Cystic fibrosis presented neonatally with meconium ileus which was treated surgically. CF was confirmed by positive pilocarpine iontophoresis sweat test at 10 days. Conventional treatment for $\mathrm{CF}$ was given. The clinical course of the lung disease was mild. At the age of 5 years a nasal polypectomy was performed. Liver function tests altered from this age onwards. Hepatomegaly was observed two years later. He was admitted to hospital at the age of $11 \frac{1}{2}$ years for intravenous antibiotic treatment because of pulmonary infection. Pseudomonas aeruginosa was isolated from sputum cultures soon after this, but not repeatedly. At $13 \frac{1}{2}$ years he was asymptomatic with discrete clubbing, hepatomegaly of $4 \mathrm{~cm}$, and pubertal state A1P1G2. Weight and height were between the 10th and 25th centiles. Respiratory function tests for FVC, FEV PEFR were $89 \%, 83 \%$, and $76 \%$ of predicted, respectively.

Schwachman score was good $(80 / 100)$ as was the Chrispin-Norman score at $6 / 38$. ALT (71 IU/l, normal <29 IU/l) and $\gamma \mathrm{GT}$ (106 IU/l, normal < $40 \mathrm{IU} / \mathrm{l})$ values were raised. Ultrasonographic investigations showed marked liver and pancreatic steatocirrhosis.

In conclusion, we present a patient homozygous for a frameshift mutation in the $R$ domain of the CFTR. He has severe pancreatic and hepatic symptoms, but lung disease is mild. The $2184 \mathrm{delA}$ mutation predicts a stop codon 38 amino acids further in the same exon of the CFTR, but it is not known whether this mutation results in the total absence of the CFTR or in a partially functional protein. Study of the CFTR protein in different tissues will be necessary to resolve this. At the moment, the question remains whether these studies will clarify the difference in disease expression in tissues.

W LISSENS DESMYTTERE M BONDUELLE I DAB I LIEBAERS

Departments of Medical Genetics and Pediatrics, University Hospital VUB
Laarbeeklaan 101 Laarbeeklaan 101,
1090 Brussels, Belgium

B MERCIER M P AUDREZET C FEREC Centre de Biogénétique, 46 Rue Félix le Dantec, 29275 Brest France.

1 Cutting G, Kasch L, Rosenstein B, et al. Two patients with cystic fibrosis, nonsense mutations in each cystic fibrosis gene, and mild pulmonary disease. $N$ Engl $\mathcal{f} \mathrm{Med}$ 1990;323:1685-9.

2 Gasparini P, Borgo G, Mastella G, et al. Nine cystic fibrosis patients homozygous for the CFTR nonsense mutation R1162X have mild or moderate lung disease. 7 Med Gene 1992;29:558-62.

3 Cheadle J, Al-Jader L, Goodchild M, Meredith A. Mild pulmonary disease in a cystic fibrosis
child homozygous for R553X. $\mathcal{F}$ Med Genet 1992;29:597.

4 Bonduelle M, Lissens W, Liebaers I, et al. Mild cystic fibrosis in a child homozygous for G542 cystic fibrosis in a child homozygous for G542 1991;338:189.

5 Bal J, Stuhrmann M, Schloesser M, et al. A cystic fibrosis patient homozygous for the cystic fibrosis patient homozygous for the 1991;28:715-7.

6 Shoshan T, Augarten A, Gazit E, et al. Association of a nonsense mutation (W1282X), the most common mutation in the Ashkenazi Jew ish cystic fibrosis patients in Israel, with presentation of severe disease. Am $\mathcal{F}$ Hum Gene 1992;50:222-8.

7 Wine J. No CFTR: are CF symptoms milder? Nature Genet 1992;1:10. 